\title{
Analysis of the mid-latitude weather regimes in the 200 -year control integration of the SINTEX model
}

\author{
Susanna Corti $\left({ }^{1}\right)$, Silvio Gualdi $\left({ }^{2}\right)$ and Antonio Navarra $\left({ }^{2}\right)$ \\ ${ }^{1}$ ) Istituto di Scienze dell'Atmosfera e del Clima, CNR, Bologna, Italy \\ ${ }^{2}$ ) Istituto Nazionale di Geofisica e Vulcanologia, Roma, Italy
}

\begin{abstract}
Recent results indicate that climate predictions require models which can simulate accurately natural circulation regimes and their associated variability. The main purpose of this study is to investigate whether (and how) a coupled model can simulate the real world weather regimes. A 200-year control integration of a coupled GCM (the «SINTEX model») is considered. The output analysed consists of monthly mean values of Northern Hemisphere extended winter (November to April) 500-hPa geopotential heights. An Empirical Orthogonal Function (EOF) analysis is first applied in order to define a reduced phase space based on the leading modes of variability. Therefore the principal component PDF in the reduced phase space spanned by two leading EOFs is computed. Based on a PDF analysis in the phase space spanned by the leading EOF1 and REOF2, substantial evidence of the nongaussian regime structure of the SINTEX northern winter circulation is found. The model Probability Density Function (PDF) exhibits three maxima. The 500-hPa height geographical patterns of these density maxima are strongly reminiscent of well-documented Northern Hemisphere weather regimes. This result indicates that the SINTEX model can not only simulate the non-gaussian structure of the climatic attractor, but is also able to reproduce the natural modes of variability of the system.
\end{abstract}

Key words Coupled General Circulation Model systematic error - non-linear dynamics - flow regimes

\section{Introduction}

Previous studies have assumed that anthropogenic (and natural) climate change can be understood in terms of a linear superposition of a response to external forcing on unchanging background variability. While this may be an adequate description of large-scale temperature changes, there is evidence that changes in atmos-

Mailing address: Dr. Susanna Corti, Istituto di Scienze dell'Atmosfera e del Clima, CNR, Via Gobetti 101, 40129, Bologna, Italy; email: s.corti@isac.cnr.it pheric circulation may be better characterized as certain naturally-occurring weather regimes becoming more or less prevalent in response to a given external forcing. In particular, based on analyses of mid-tropospheric geopotential data, a recent study (Corti et al., 1999) suggested that trends in northern-hemispheric climate over the latter decades can be interpreted in terms of a change in the relative probability of naturallyoccurring atmospheric circulation regimes, like the «Cold Ocean Warm Land» (Wallace et al., 1996) and «Arctic Oscillation» (Thomson and Wallace, 1998) patterns, rather than a simple linear shift in the mean climate with superimposed noise. This result supports a non-linear dynamical paradigm that the climate response to anthropogenic forcing may project principally on the dominant patterns of natural climatic variability (Palmer, 1999). 
If valid, this new conceptual model has important implications both for the interpretation of the observed signal and for future climate change. In particular, considering this nonlinear perspective, the prediction of anthropogenic climate change require models which can simulate accurately natural circulation regimes and their associated variability, even though the dominant timescale of such variability may be much shorter than the climate change signal itself. More generally, these models should be able to simulate the non-gaussian characteristics of the climate attractor. To date, AtmosphericOcean General Circulation Models (A-OGCMs) have not been tested in this way to any great extent. The main purpose of the present study is to explore how well the SINTEX model (Gualdi et al., 2003) is capable of simulating the kind of regime behaviour outlined above.

The paper is structured as follows. The 500 hPa geopotential height model wintertime climatology is presented in Section 2, while Section 3 is devoted to the EOF analysis of the monthlymean of the Northern Hemisphere extended winter (November to April) 500-hPa geopotential height as simulated by the model. In Section 4 geographical patterns of the four (simulated) atmospheric regimes, together with the corresponding probability density estimation, are shown. Preliminary conclusions are to be found in Section 5.

\section{Simulation of the wintertime climatology}

This study analyses a 200-year integration of a coupled GCM (the «SINTEX model»). The atmospheric component of the coupled model is ECHAM4 (at T30 resolution), developed at the Max-Planck Institute (Hamburg). The oceanic component is the OPA model developed by LODYC (Paris). More detailed information on these models and the coupling strategies are to be found in a companion paper in this special issue (Gualdi et al., 2003).

The output analysed consists of monthly mean values of Northern Hemisphere extended winter (November to April) 500-hPa geopotential height. Figure 1a-f compares the cold-season model climatology (of 500-hPa geopotential height) with the corresponding NCEP/NCAR climatology over the period 1958-1998 (Kalnay et al., 1996). The full field mean error and the model and observed standard deviations are shown in the left column, while panels on the right column show the eddy component of the fields (i.e. their deviations from zonal means).

Just looking at the full height fields error in panel (a), it is evident that the northern extratropical mean flow has a level of realism comparable to that of higher resolution GCMs, with systematic errors reaching a maximum amplitude of about $80 \mathrm{~m}$ in the North Pacific and Polar regions. The error pattern exhibits a quite zonal symmetry: there is a general overestimation of the mean height north of $60^{\circ} \mathrm{N}$, partially counterbalanced, a part for South Europe, by a negative error south of this latitude. The model distribution of low-frequency variability (compare standard deviation patterns in panel (b) and panel (c)) is very realistic: the three maxima in the North Pacific (shifted south-eastward though), North Atlantic and North-Western Siberia are fairly well reproduced, albeit about 10 to $20 \%$ lower than observed.

Comparing the eddy fields in panel (d) and panel (e), the simulated amplitude of the stationary waves is fairly realistic in the Pacific sector, overestimated by $20 \%$ in the Euro-Atlantic region, and about one third of the observed amplitude over the eastern part of North America. However, the systematic model error seems dominated by its eddy component ( $c f$. panels (a) and (f)) everywhere except for North-Eastern Asia.

\section{Empirical Orthogonal Function (EOF) analysis}

The leading variability patterns of the model atmosphere were searched for by calculating Empirical Orthogonal Functions (EOFs) of monthly $500 \mathrm{hPa}$ height anomalies (the seasonal cycle has been removed from the data by computing anomalies with respect to the longterm monthly mean). Figure 2 shows the first six EOFs patterns from the 200-years model integration, whilst the corresponding patterns computed from the observed data set (NCEP 1958-1998 reanalyses) are displayed in fig. 3. 

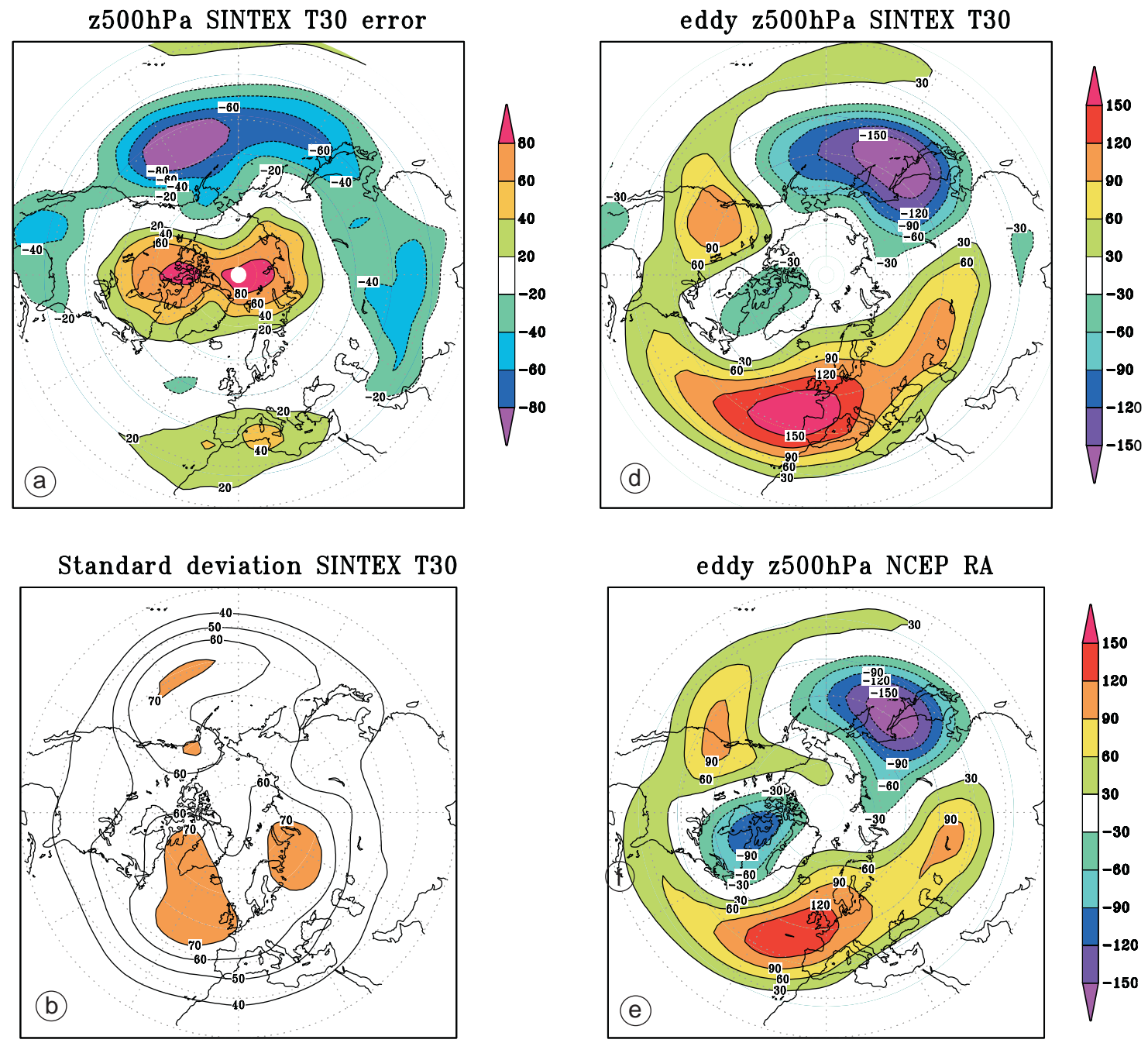

\section{Standard deviation NCEP RA}
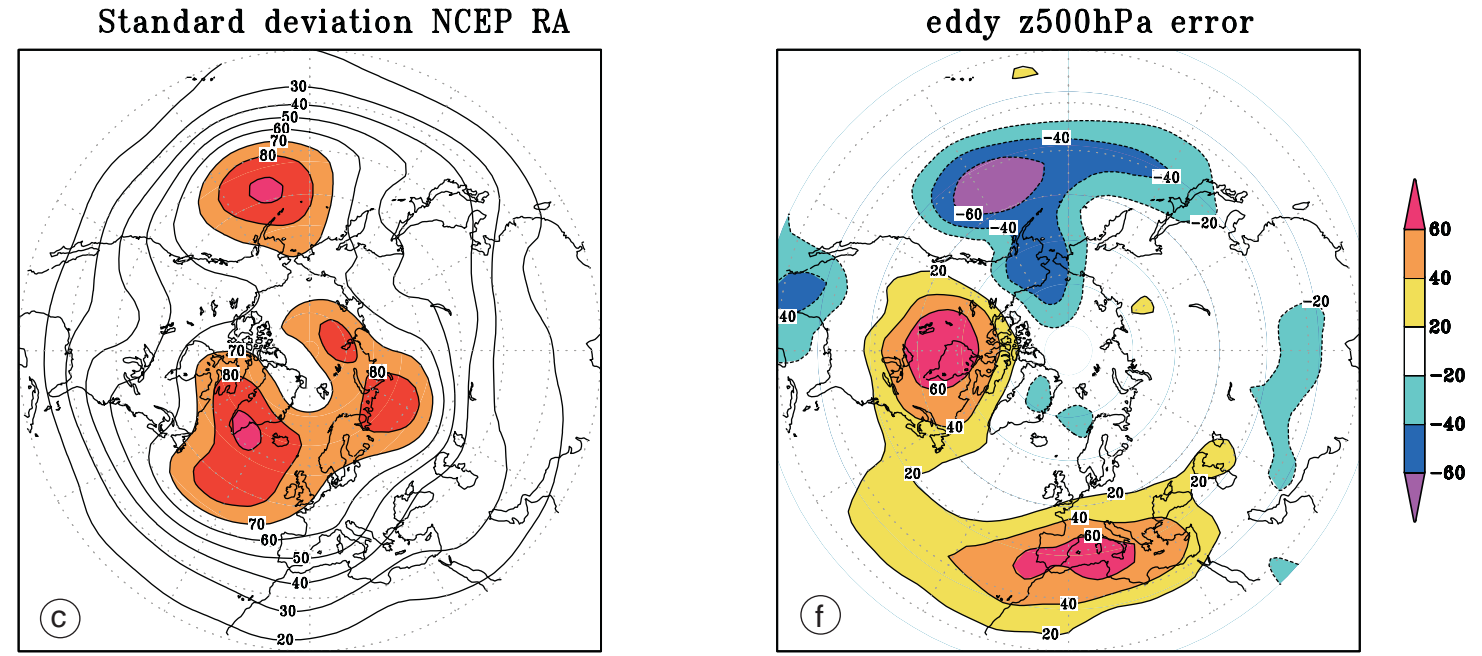

Fig. 1a-f. Statistics of $500 \mathrm{hPa}$ geopotential height from NDJFMA 200-year integration of the SINTEX model and from the 41-year (1958-1998) of NCEP reanalysis. a) Mean model error (SINTEX-NCEP), contour interval $20 \mathrm{~m}$; b,c) model and observed standard deviation, contour interval $10 \mathrm{~m}$; d) eddy component of the $500 \mathrm{hPa}$ model mean field, contour interval $30 \mathrm{~m}$; e) as in (d) but for NCEP reanalysis; f) eddy model error (SINTEXNCEP), contour interval $20 \mathrm{~m}$. 
EOF1 ndjfma SINTEX MODEL 200yr 17.1\%
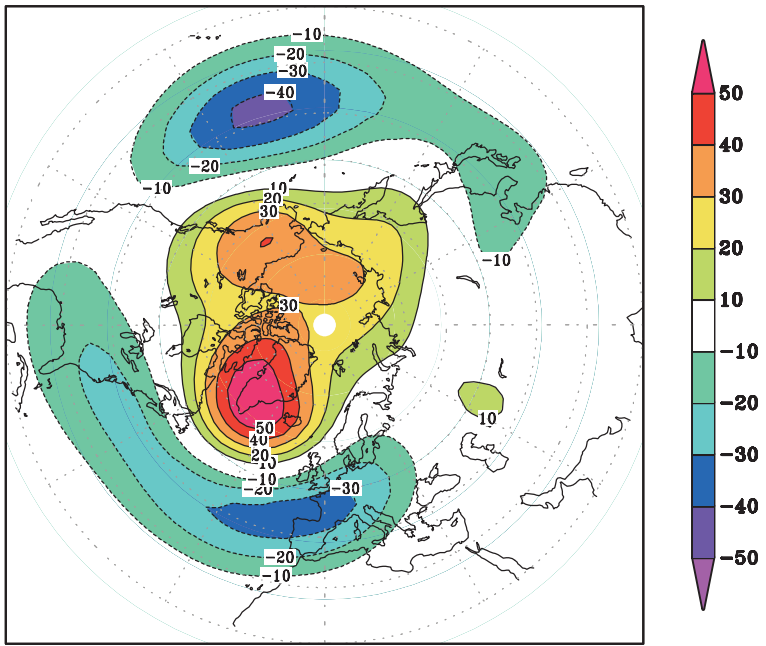

EOF2 ndjfma SINTEX MODEL 200yr 11.1\%
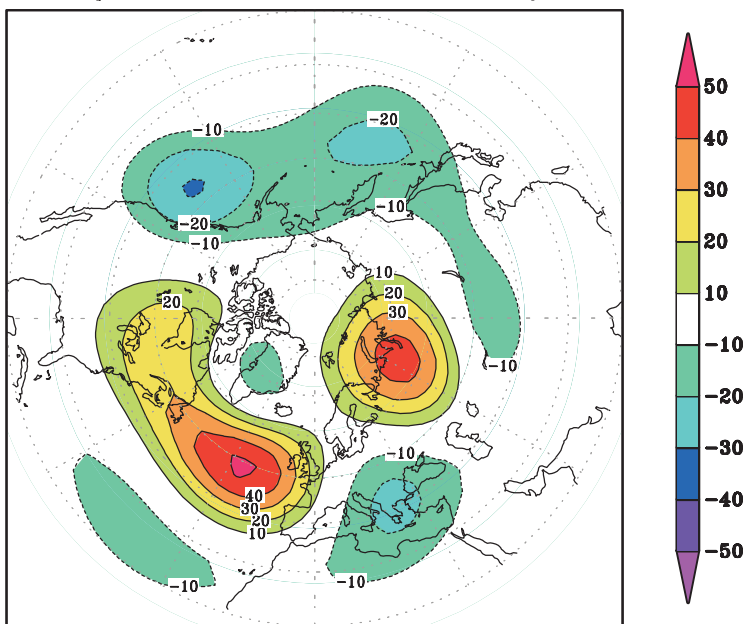

EOF3 ndjfma SINTEX MODEL 200yr 8.4\%
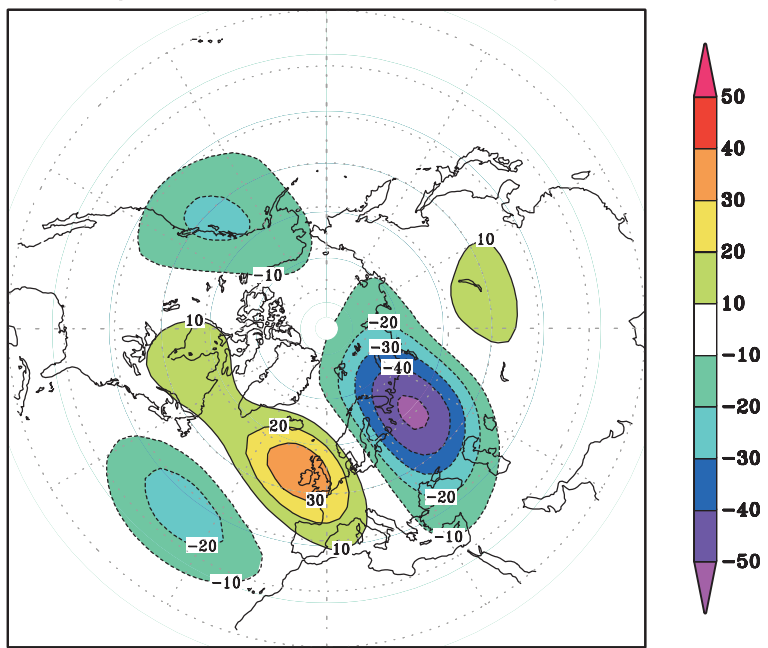

EOF4 ndjfma SINTEX MODEL 200yr 7.1\%
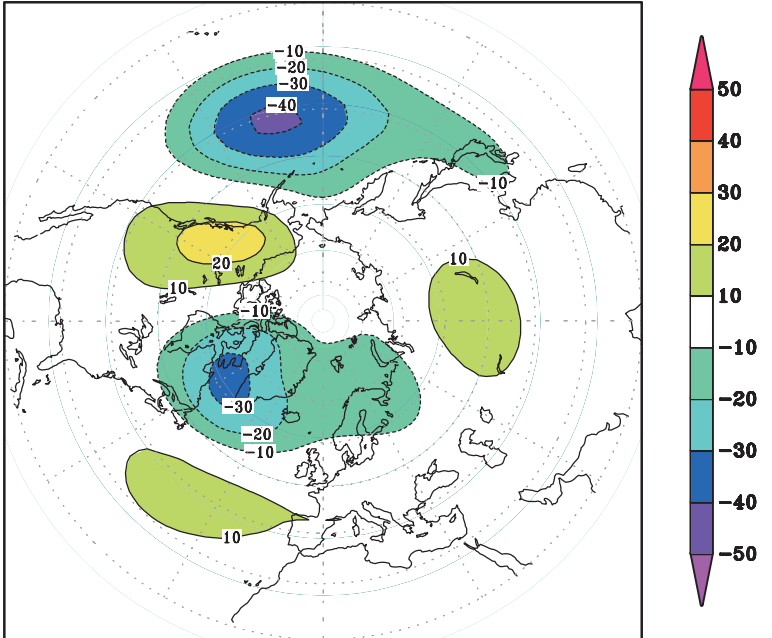

EOF5 ndjfma SINTEX MODEL 200yr 6.5\%
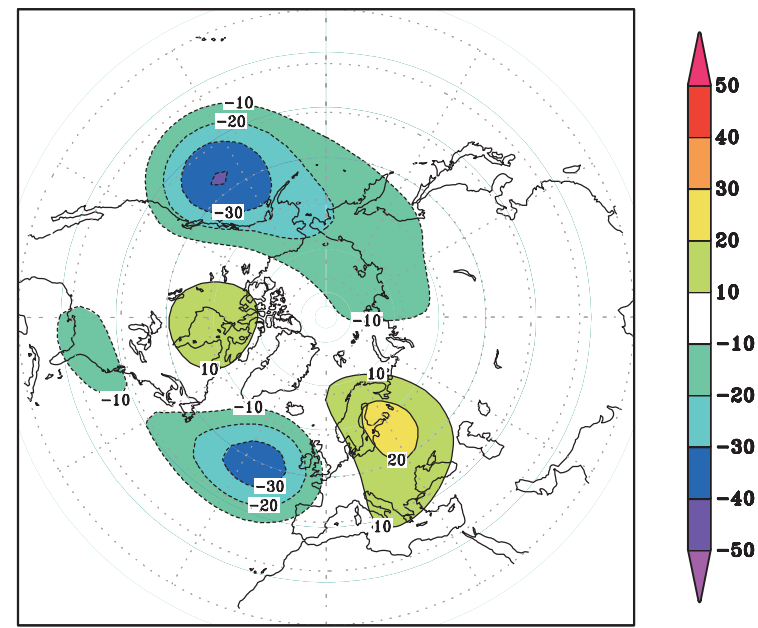

EOF6 ndjfma SINTEX MODEL 200yr 5.8\%

Fig. 2. The SINTEX model simulation: geographical distribution of 500-hPa-geopotential height associated with the six dominant Empirical Orthogonal Functions. EOFs, contour interval $10 \mathrm{~m}$. 
EOF 1 ndjfma 58/98 NCEP RA $16 \%$

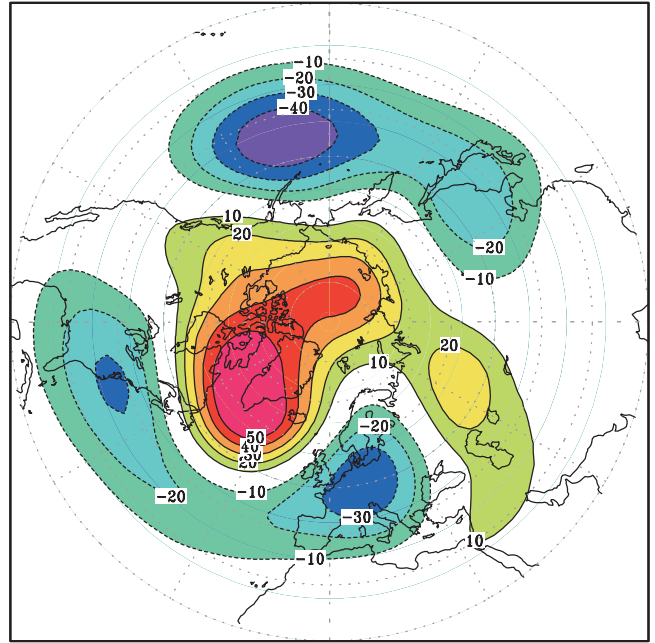

EOF2 ndjfma 58/98 NCEP RA $12 \%$

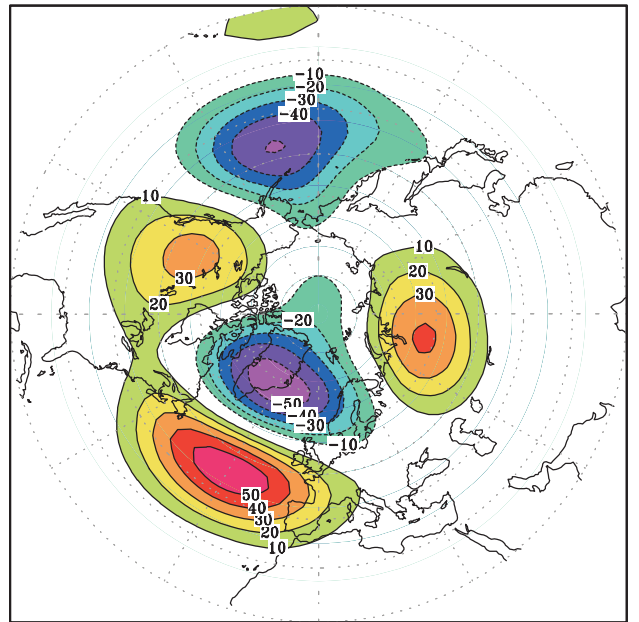

EOF3 ndjfma 58/98 NCEP RA $9.8 \%$

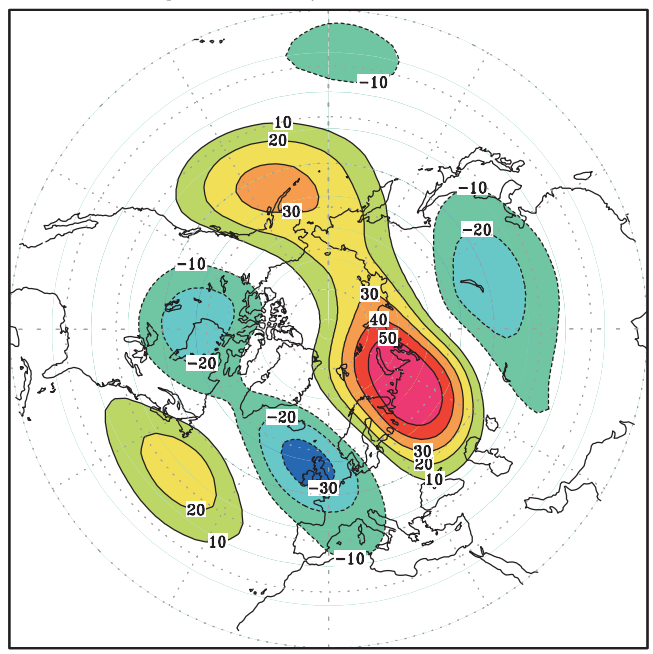

E0F4 ndjfma 58/98 NCEP RA $8.2 \%$

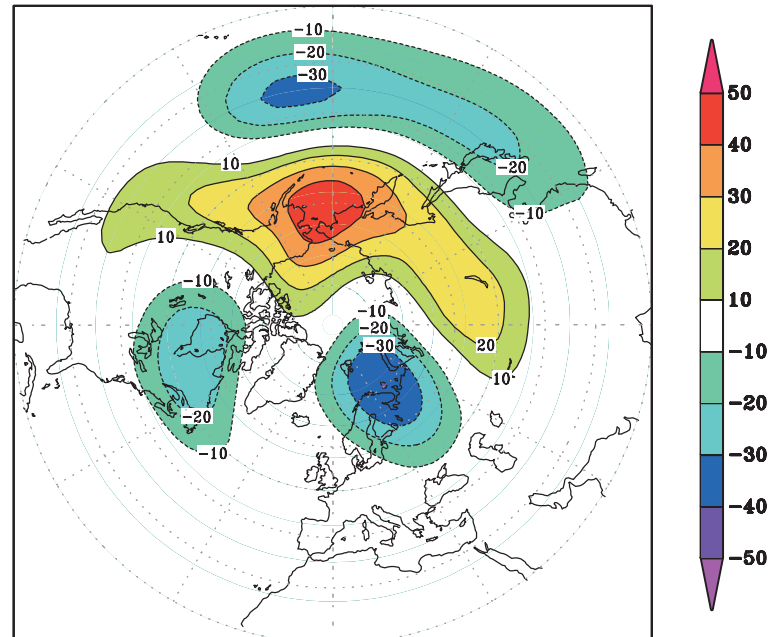

EOF5 ndjfma 58/98 NCEP RA $7.2 \%$
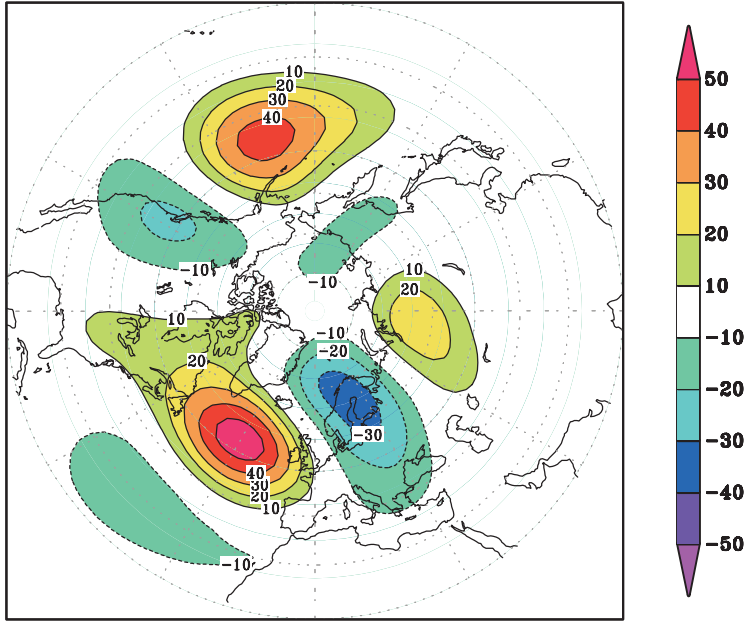

EOF6 ndjfma 58/98 NCEP RA $5.8 \%$

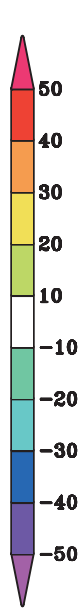

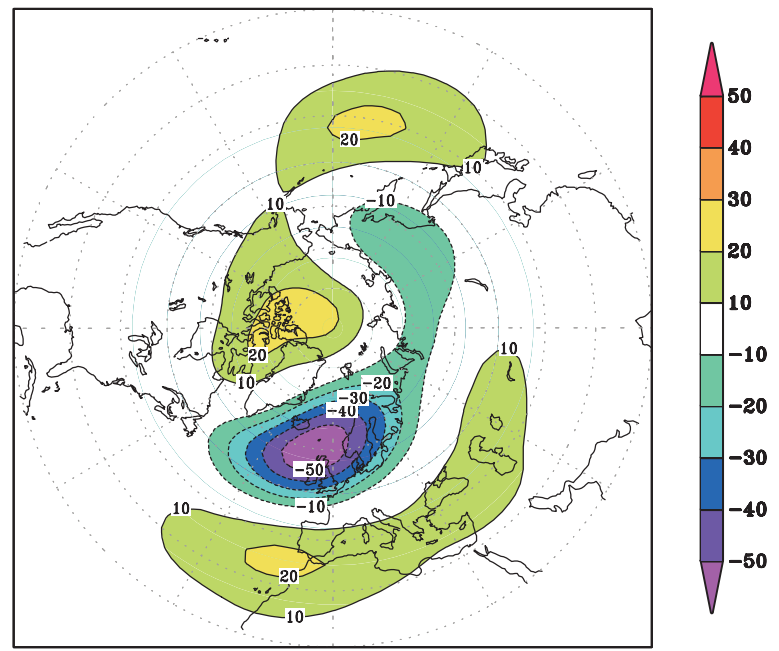

Fig. 3. As fig. 2, but for the observed fields (1958-1998 NCEP reanalysis). Contour interval $10 \mathrm{~m}$. 


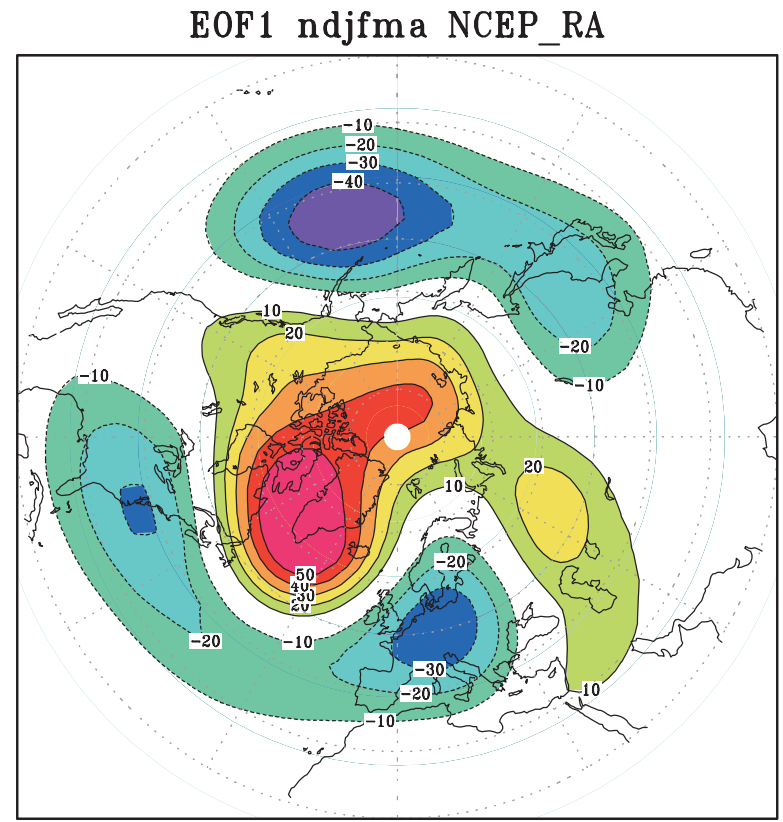

EOF1 ndjfma SINTEX MODEL 200yr

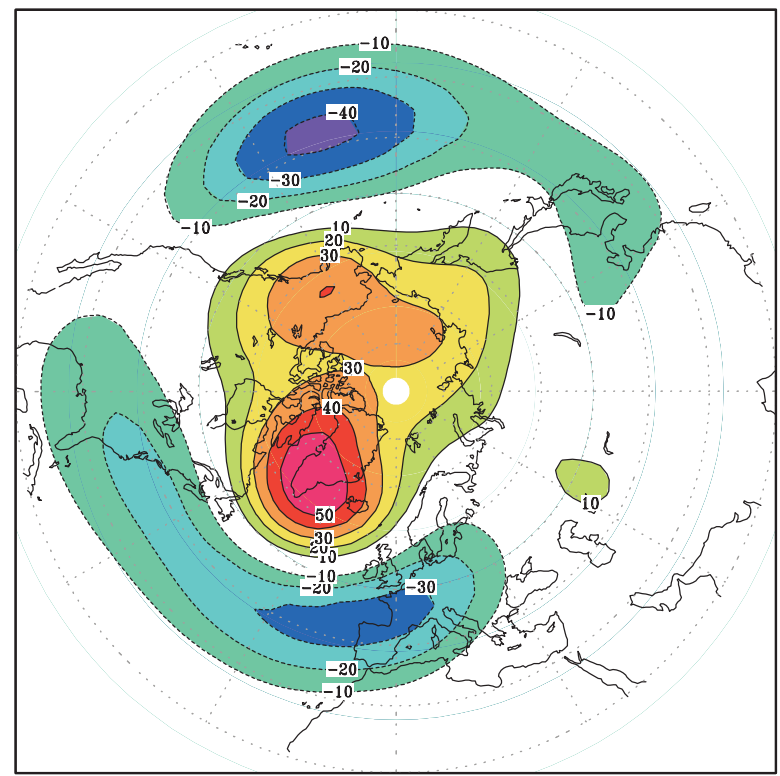

REOF2 ndjfma SINTEX MODEL 200yr
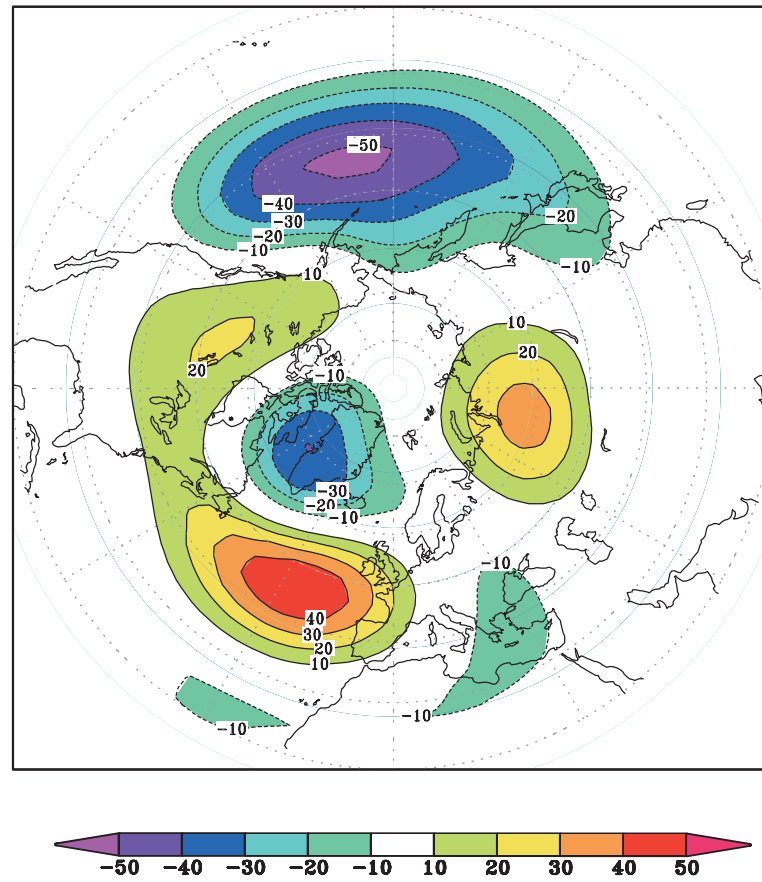

Fig. 4. Observed and simulated leading EOFs at 500-hPa-geopotential height. Left column: first leading EOFs from the NCEP reanalysis data set; right column: first EOF (EOF1) and second rotated EOF (REOF2) from the SINTEX model integration, contour interval $10 \mathrm{~m}$.

The first observed mode (EOF1) is characterised by two dominant centres of opposite sign (signs of anomalies are immaterial in EOF analysis) over the North Pacific around $150^{\circ} \mathrm{W}$ in the Gulf of Alaska and over the North Atlantic around $45^{\circ} \mathrm{W}$ on the southern part of Greenland. To the southwest and to the southeast of the Atlantic centre, there exist weaker anomaly centres contributing together to the wave trainlike appearance in the Atlantic-to-Eurasian sector. 
The first model EOF bears a strong resemblance to its observed counterpart in the Pacific sector, while the Atlantic wave train-like is reduced to a north-south dipole. The observed EOF2 is also characterised by two dominant centres, of equal sign in this case, over slightly shifted positions in the North Pacific and in the North Atlantic. This time, the Atlantic feature is consistent with the structure of the North Atlantic Oscillation (van Loon and Rogers, 1978). This observed mode does not have a counterpart in the second model EOF, however the two patterns do not differ too much. The wavetrain-like which characterises the global structure of EOF3 is captured by the model and almost all the centres of action characterising the remaining EOFs are reproduced, even though partially, in the SINTEX model simulation.

\section{Weather regimes in the SINTEX model}

Following the line of Corti et al. (1999), we defined a reduced two-dimensional phase space based on the leading patterns (EOFs) of the model low-frequency variability. But, in order to compare model and observed results, model EOFs 2 and 4 was rotated to obtain a pattern as similar as possible to the observed EOF2. We shall refer to such a pattern, shown in fig. 4 , as to rotated-EOF2 (REOF2).

Figure 5 compares the PDF of the projection coefficients of the monthly-mean high field, in the reduced phase space spanned by EOF1 and REOF 2 and the «observed PDF» found by Corti et al. (1999). The same interactive gaussiankernel estimator has generated both distributions. The model PDF exhibits three maxima labelled $\mathrm{A}^{\prime}, \mathrm{B}^{\prime}$ and $\mathrm{C}^{\prime}$, which appear to be consistent with the corresponding, observed ones. The fourth observed maximum, labelled D, does not have a counterpart in the SINTEX PDF, however, close to its expected location, there is a large plateau well separated from the other maxima (this plateau has been labelled $\mathrm{D}^{\prime}$ in the figure).

The geographical patterns of the three density maxima and that corresponding to the mean value of plateau $\mathrm{D}^{\prime}$, are illustrated in fig. 6, where they are shown as departures from the 200-year mean $500 \mathrm{hPa}$ height.
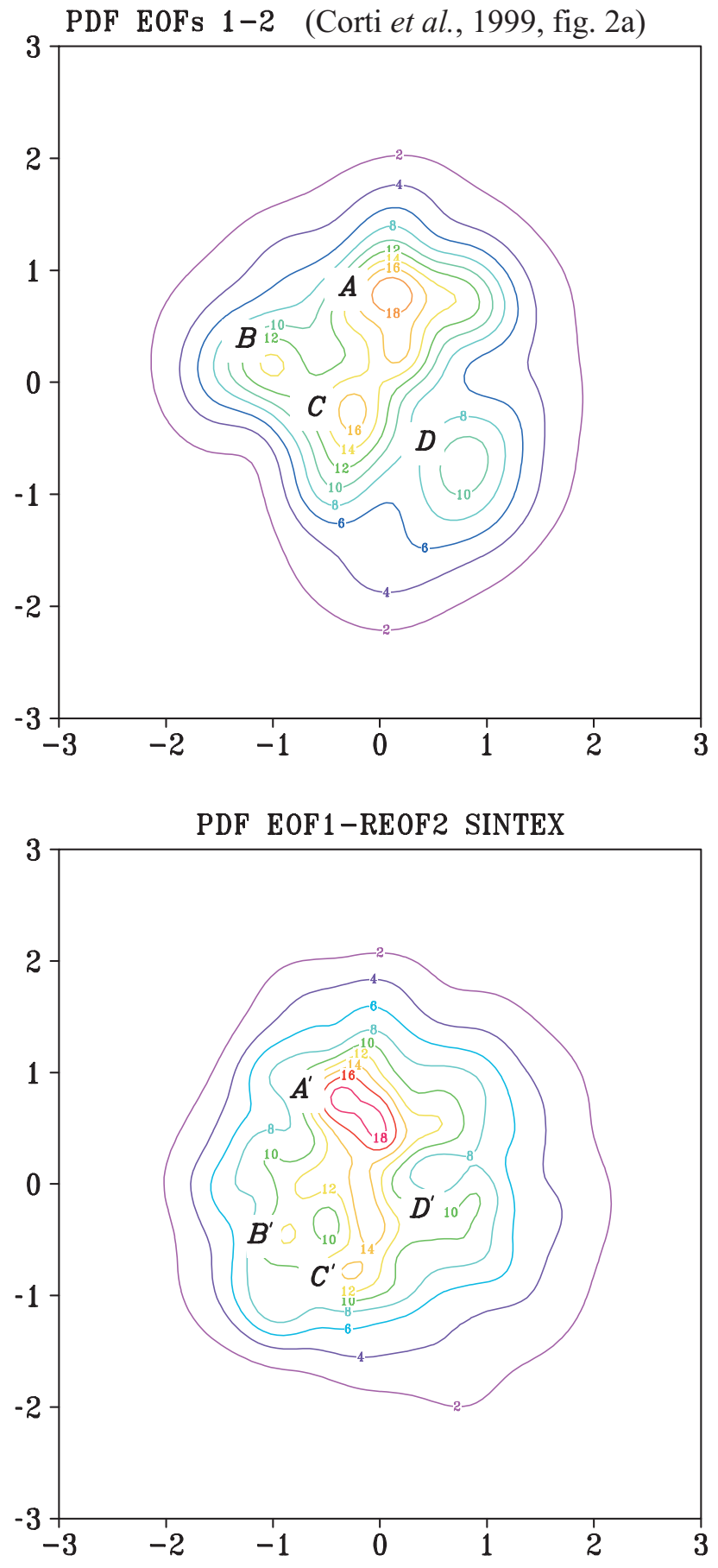

Fig. 5. Evidence of the non-gaussian characteristic of the climate attractor. Top panel: atmospheric state vector PDF based on monthly-mean 500-hPa geopotential height in the space spanned by the two dominant EOFs (see fig. 4, left column). There are four maxima labelled A, B, C, D.; bottom panel: atmospheric state vector PDF based on monthly-mean 500$\mathrm{hPa}$ geopotential height from the SINTEX 200 year integration in the space spanned by EOF1 and REOF2 (see fig. 4, right column). There are three maxima labelled $\mathrm{A}^{\prime}, \mathrm{B}^{\prime}, \mathrm{C}^{\prime}$ and a large plateau labelled $\mathrm{D}^{\prime}$. 

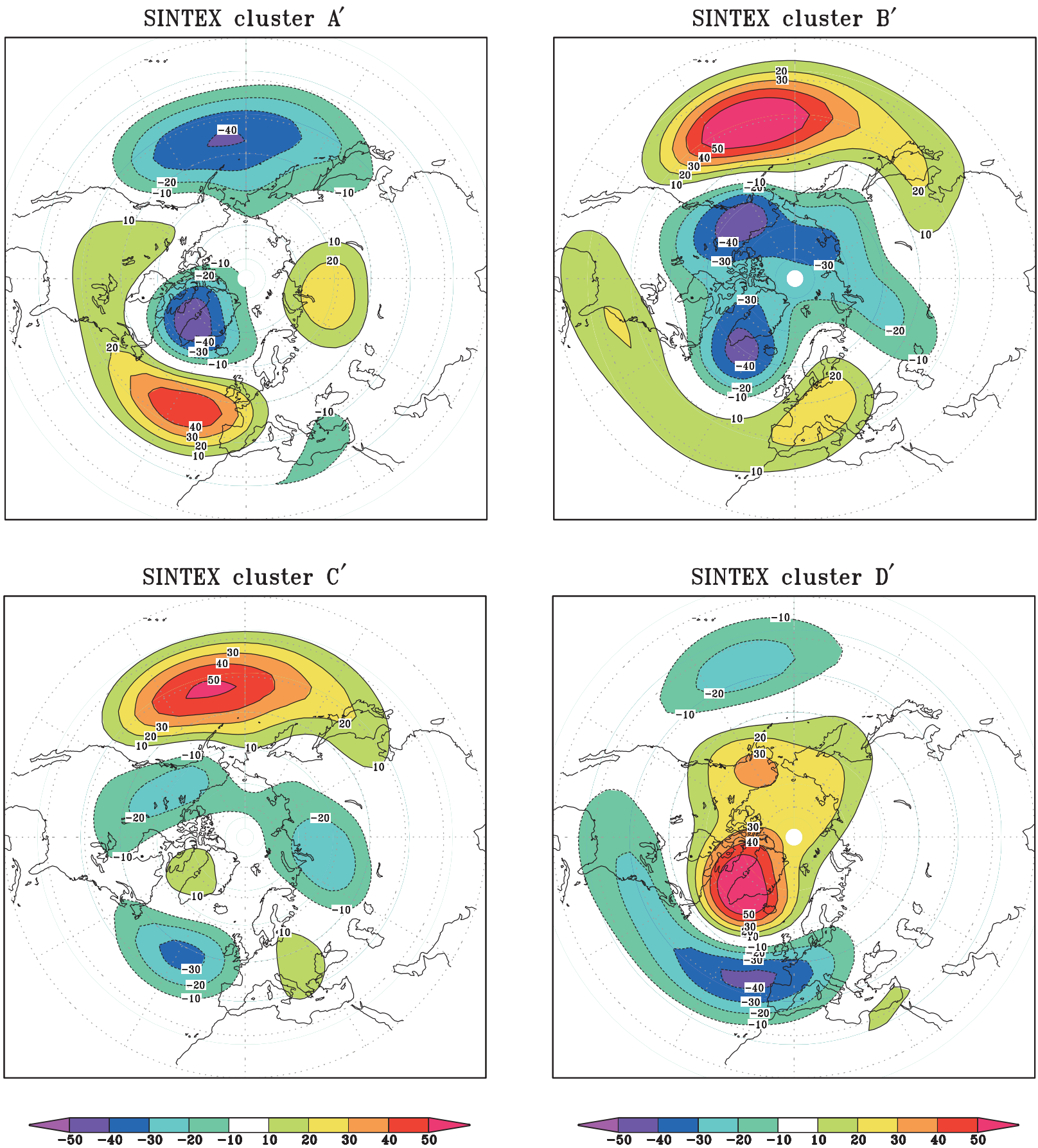

Fig. 6. Geographical patterns of the four atmospheric regimes in the SINTEX model. Shown is the geographical distribution of 500-hPa geopotential height anomaly associated with clusters $\mathrm{A}^{\prime}$ (the «Cold Ocean Warm Land» regime), $\mathrm{B}^{\prime}, \mathrm{C}^{\prime}$ and $\mathrm{D}^{\prime}$ (the «Arctic Oscillation» regime). Contour interval $10 \mathrm{~m}$.

All the simulated regimes have an observed counterpart (see fig. 7 for comparison) well documented in the literature (e.g., Mo and Ghil, 1988; Molteni et al., 1990; Cheng and Wallace,
1993; among others). The circulation associated with cluster $A^{\prime}$ is characterised by a strong jet stream, displaced southward of its climatological mean latitude over the Central Pacific, with a 
strongly diffluent flow downstream leading into a long-wave ridges over the Rockies and, over the Euro-Atlantic region, by the positive polarity of the North Atlantic Oscillation, i.e. a strength of the westerlies along the node in the NorthAtlantic dipole pattern. Furthermore, this kind

\section{cluster A}
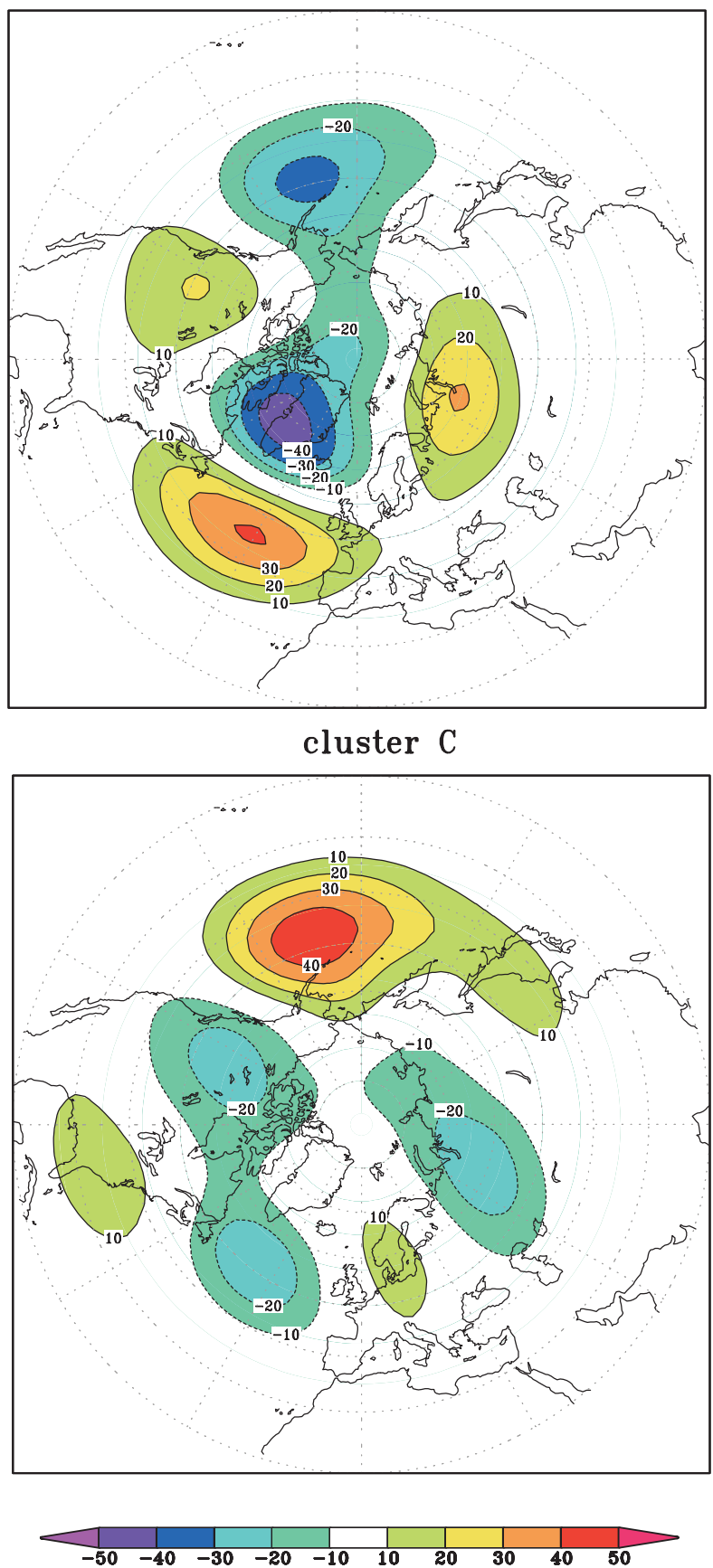

of atmospheric flow is associated with above normal temperatures over Alaska, Western Canada, Europe, most of Russia and NorthEastern United States. Both clusters B' and $C^{\prime}$ contain elements of the PNA pattern in its negative polarity, and are associated with high
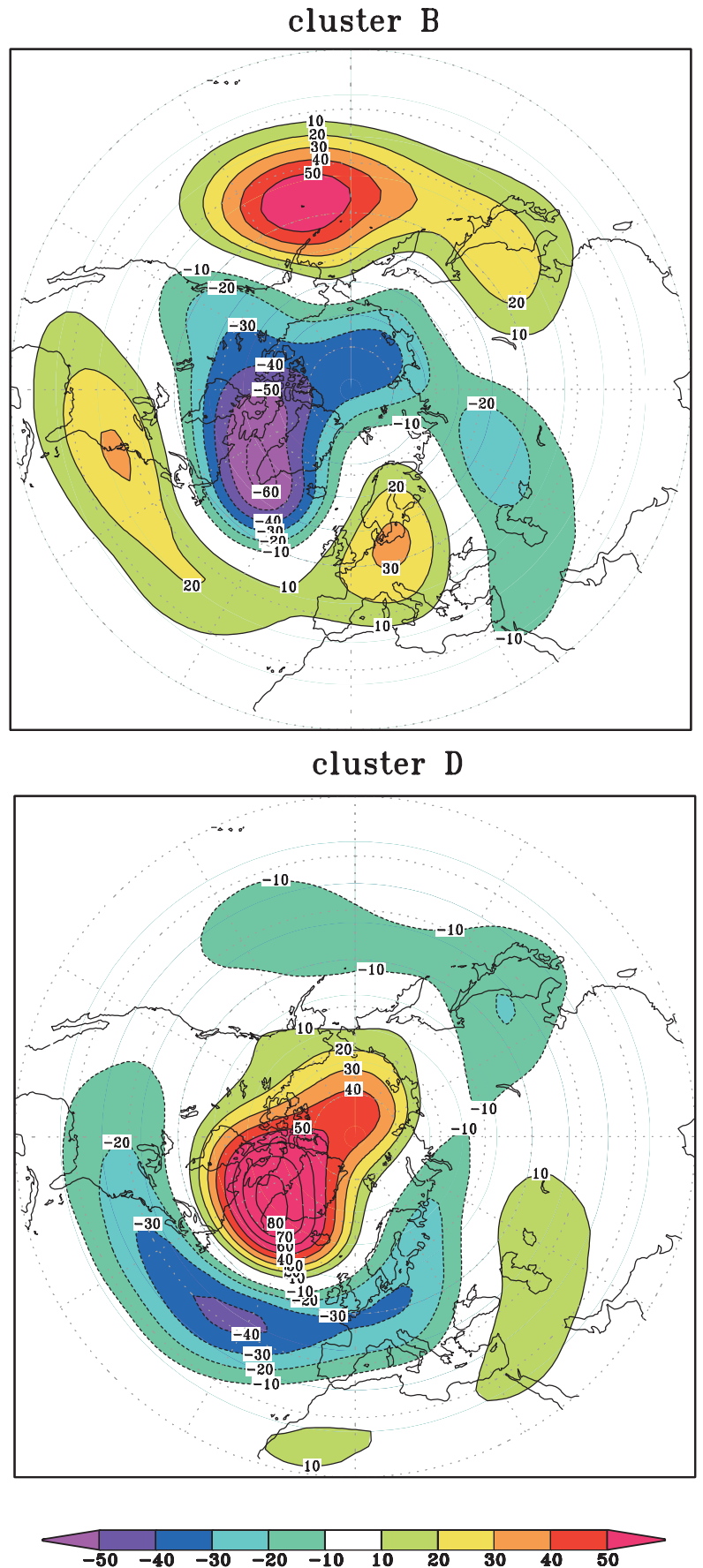

Fig. 7. As fig. 6, but for the observed data set (after Corti et al., 1999). Same contour interval. 
amplitude ridges (Alaska blocking) over NorthEastern Pacific and with cold air outbreaks over the U.S. Pacific Northwest. Cluster B' projects onto the positive North Atlantic Oscillation as well. Finally cluster $\mathrm{D}^{\prime}$ resembles the NAO in its negative polarity and it is well correlated with the $500 \mathrm{hPa}$ height component of the Arctic Oscillation (Thompson and Wallace, 1998). It is associated with blocking episodes over the Atlantic and is characterised by cold weather over the North-Eastern U.S. and South-Eastern Canada and Scandinavia.

\section{Concluding remarks}

The previous sections presented the SINTEX model's skill in simulating the low-frequency variability features of the winter midlatitude atmospheric circulation. The model performances have been assessed comparing first the simulated mean state and variability with the corresponding statistics from observational data sets and then evaluating the model capability of simulating the non-gaussian structure of the climatic attractor.

Taking into account the limitations imposed by the «coarse» atmospheric horizontal resolution, the overall performance of the SINTEX model in simulating the leading patterns of the Northern Hemisphere low-frequency variability is quite accurate. It was found that the SINTEX model not only can simulate the non-gaussian structure of the climatic attractor, but is also able to reproduce the natural modes of variability of the system.

The main results of our analyses can be summarised as follows.

- The cumulative variance explained by the first six EOFs, $56 \%$ of total, is comparable to the observed one $(59 \%)$.

- All the leading EOFs, apart EOF2 and EOF4, have an observed counterpart which explains almost the same amount of total variance.

- Furthermore, SINTEX EOF2 and EOF4 are not so far from observed EOF2 and EOF4, rather they can be thought of as a linear combination of these patterns.

- Based on a PDF analysis in the phase space spanned by the leading EOF1 and REOF2, substantial evidence of the non-gaussian regime structure of the SINTEX northern winter circulation has been found.

- The model PDF exhibits three maxima labelled $\mathrm{A}^{\prime}, \mathrm{B}^{\prime}$ and $\mathrm{C}^{\prime}$, which have an observed counterpart.

- The spatial structure of regime $A^{\prime}$ (the most populated) is strongly reminiscent of the pattern found by linear regression analysis between monthly-mean Northern Hemisphere mean surface air temperature and $500 \mathrm{hPa}$ height (Wallace et al., 1996). Essentially, this pattern denotes the 500-hPa geopotential height manifestation of the so-called «Cold Ocean Warm Land» pattern, which describes recent climate change in surface air temperature on decadal timescale. The fact that this pattern has been detected, as a regime, in a control run (i.e. no anomalous forcing) of a coupled model represents further evidence that COWL does have meaning not only in relation to hemispheric surface air temperature, but it is a natural mode of atmospheric variability.

- The height anomalies associated with clusters $\mathrm{B}^{\prime}$ and $\mathrm{C}^{\prime}$ have both a projection onto the negative Pacific North American (PNA) pattern, but cluster $\mathrm{B}^{\prime}$ projects onto the positive North Atlantic Oscillation (NAO) as well.

- Cluster $\mathrm{D}^{\prime}$, which is not a PDF maximum, but corresponds to the mean value of plateau $\mathrm{D}^{\prime}$, is the least populated in the model (and also in the real world). It is extremely well correlated with the $500 \mathrm{hPa}$ height component of the Arctic Oscillation (Thompson and Wallace, 1998) in its negative phase; furthermore it is strongly reminiscent of regime $G^{\prime}$ of Cheng and Wallace (1993) and of Kimoto and Ghil's (1993) regime BNAO.

The results outlined above indicate that the SINTEX model is able to reproduce the natural modes of variability of the system. However, we have not so far discussed the model bias in the regime frequencies. In the 200-year model integration, cluster $\mathrm{A}^{\prime}$ is overwhelmingly the most populated cluster, whereas, for example, cluster $D^{\prime}$ is very much a secondary regime. In other words, on a monthly time-scale, the model circulation is somehow biased toward the $\mathrm{A}^{\prime}$ regime. A possible explanation of this behaviour can be found in the fact that there is spatial 
correspondence between the systematic error patterns (fig. 1a,f) and the cluster $\mathrm{A}^{\prime}$ anomaly. In fact, the spatial correlation between the eddy systematic error (projected on the subspace spanned by EOF1 and REOF2) and the cluster $\mathrm{A}^{\prime}$ pattern is $96 \%$. This result supports the notion (Palmer, 2001) that the systematic error could be interpreted in terms of model bias towards the most intensely populated regime. Following this perspective, (most of) the systematic error is determined by the model overestimation of the dominant regime (and consequent underestimation of the secondary regimes) which could be due to an underestimation, by the model, of transient variability. Let us assume that the cluster $\mathrm{A}$ is the most stable regime (in the Pacific/North American sector this circulation regime projects onto the positive phase of the Pacific North American pattern (Wallace and Gutzler, 1981) which is known to be a relatively stable pattern (Palmer, 1988)) and that the SINTEX model can simulate the circulation regimes but with inadequate small-scale variability to trigger regime transitions. In this case, as suggested by Molteni and Tibaldi (1990), the most stable circulation regime will become overpopulated. In order to investigate this hypothesis a detailed analysis of the model simulation of the highfrequency variability patterns related to regime transitions is currently under way.

\section{Acknowledgements}

This work was supported by the EC SINTEX project under contract ENV4-CT98-0714.

\section{REFERENCES}

Cheng, X. and J.M. WAllace (1993): Cluster analysis of the Northern Hemisphere wintertime 500-hPa height field: spatial patterns, J. Atmos. Sci., 50, 2674-2696.
CorTi, S., F. Molteni and T.N. PALMER (1999): Signature of recent climate change in frequencies of natural atmospheric circulation regimes, Nature, 398, 799-802.

Gualdi, S., A. NAVARRA, E. Guilyardi and P. Delecluse (2003): Assessment of the tropical Indo-Pacific climate in the SINTEX CGCM, Ann. Geophysics, 46 (1), 1-26 (this volume).

Kalnay, E., M. Kanamitsu, R. Kistler, W. Collins, D. DeAVEn, L. GANDin, M. IREDEll, S. SAHA, G. White, J. WoOllen, Y. Zhu, M. Chelliah, W. EbisuZaKi, W. HigGins, J. JANOWIAK, K.C. MO, C. ROPELEWSKI, J. WANG, A. LEETMAA, R. REYNOLDS, R. JENNE and D. JOSEPH (1996): The NCEP/NCAR 40-Year Reanalysis Project, Bull. Am. Meteorol. Soc., 77, 437-471.

Kimoto, M. and M. GHIL (1993): Multiple flow regimes in the Northern Hemisphere winter, part I: methodology and hemispheric regimes, J. Atmos. Sci., 50, 2674-2696.

Mo, K.C. and M. GHIL (1988): Cluster analysis of multiple planetary flow regimes, J. Geophys. Res., 93D, 10,92710,952 .

Molteni, F. and S. TIBALDI (1990): Regimes in the wintertime circulation over northern extratropics, part II: consequences for dynamical predictability, $Q . J . R$. Meteorol. Soc., 116, 1263-1288.

Molteni, F., S. TiBALDI and T.N. PALMER (1990): Regimes in the wintertime circulation over northern extratropics, I: observational evidence, Q. J. R. Meteorol. Soc., 116, 31-67.

PALMER, T.N. (1988): Medium and extended range predictability and stability of the Pacific North American mode, Q. J. R. Meteorol. Soc., 114, 691-713.

PALMER, T.N. (1999): A nonlinear dynamical perspective on climate prediction, J. Climate, 12, 575-591

PALMER, T.N. (2001): A nonlinear dynamical perspective on model error: a proposal for non-local stochastic-dynamic parametrization in weather and climate prediction models, Q. J. R. Meteorol. Soc., 127, 279-304.

Thompson, D.W. and J.M. WALlace (1998): The Arctic Oscillation signature in the wintertime geopotential height and temperature fields, Geophys. Res. Lett., 25, 1297-1300.

VAN LOON, H. and J.C. RogERS (1978): The seesaw in winter temperatures between Greenland and Northern Europe, part I: general description, Mon. Weather Rev., 118, 20562081.

WALLACE, J.M. and D.S. GUTZLER (1981): Teleconnections in the geopotential height field during the northern hemisphere winter, Mon. Weather Rev., 109, 784-812

WALlACE, J.M., Y. ZHANG and L. BAJUK (1996): Interpretation of interdecadal trends in Northern Hemisphere surface air temperature, J. Climate, 9, 249-259 